\title{
Conservative oxygen therapy for mechanically ventilated adults with suspected hypoxic ischaemic encephalopathy
}

Paul Young ${ }^{1,2^{*}}$ (D), Diane Mackle ${ }^{1}$, Rinaldo Bellomo ${ }^{3,4,5,6}$, Michael Bailey ${ }^{3,5}$, Richard Beasley ${ }^{1}$, Adam Deane ${ }^{5,6}$, Glenn Eastwood ${ }^{3,4}$, Simon Finfer ${ }^{7,8}$, Ross Freebairn' ${ }^{9}$, Victoria King ${ }^{3}$, Natalie Linke ${ }^{3}$, Edward Litton ${ }^{10}$, Colin McArthur 1,11, Shay McGuinness 1,12, Rakshit Panwar ${ }^{13,14}$ on behalf of the ICU-ROX Investigators and the Australian and New Zealand Intensive Care Society Clinical Trials Group

๑ 2020 Springer-Verlag GmbH Germany, part of Springer Nature

\begin{abstract}
Purpose: Liberal use of oxygen may contribute to secondary brain injury in patients with hypoxic-ischaemic encephalopathy (HIE). However, there are limited data on the effect of different oxygen regimens on survival and neurological disability in HIE patients.

Methods: We undertook a post-hoc analysis of the 166 patients with suspected HIE enrolled in a trial comparing conservative oxygen therapy with usual oxygen therapy in 1000 mechanically ventilated ICU patients. The primary endpoint for the current analysis was death or unfavourable neurological outcome at day 180 . Key secondary outcomes were day 180 mortality, and cause-specific mortality.
\end{abstract}

Results: Patients with HIE allocated to conservative oxygen spent less time in the ICU with an $\mathrm{SpO}_{2} \geq 97 \%$ (26 h [interquartile range (IQR) 13-45 vs. 35 h [IQR 19-70], absolute difference, 9 h; $95 \%$ Cl - 21.4 to 3.4). A total of 43 of 78 patients (55.1\%) assigned to conservative oxygen and 49 of 72 patients (68.1\%) assigned to usual oxygen died or had an unfavourable neurological outcome at day 180 ; odds ratio $0.58 ; 95 \% \mathrm{Cl} 0.3-1.12 ; P=0.1$ adjusted odds ratio $0.54 ; 95 \% \mathrm{Cl} 0.23-1.26 ; P=0.15$. A total of 37 of 86 patients (43\%) assigned to conservative oxygen and 46 of 78 (59\%) assigned to usual oxygen had died by day 180 ; odds ratio $0.53 ; 95 \% \mathrm{Cl} 0.28-0.98 ; P=0.04$; adjusted odds ratio 0.56 ; $95 \% \mathrm{Cl} 0.25-1.23 ; P=0.15$. Cause-specific mortality was similar by treatment group.

Conclusions: Conservative oxygen therapy was not associated with a statistically significant reduction in death or unfavourable neurological outcomes at day 180. The potential for important benefit or harm from conservative oxygen therapy in HIE patients is not excluded by these data.

Keywords: Oxygen therapy, Cardiac arrest, Hypoxic ischemic encephalopathy, Intensive care medicine, Critical care, Randomized controlledtrial

\footnotetext{
*Correspondence: paul.young@ccdhb.org.nz

${ }^{2}$ Intensive Care Unit, Wellington Hospital, Private Bag 7902, Wellington New Zealand

Full author information is available at the end of the article
}

*A complete list of investigators in the Intensive Care Unit Randomized Trial Comparing Two Approaches to OXygen therapy (ICU-ROX) is provided in the Acknowledgments.

\section{Springer}

\section{Introduction}

Liberal use of oxygen as occurs with standard management of comatose post-cardiac arrest patients may contribute to secondary brain injury [1,2]. For example, exposure to hyperoxaemia worsens brain damage in animal models of cardiac arrest [3] and hyperoxaemia is independently associated with increased mortality risk in some observational studies in humans [4-8]. However, this association has not been shown in all studies $[9,10]$ and one potential concern 
with conservative use of oxygen therapy is that it might increase exposure to hypoxaemia, which is strongly associated with adverse outcomes in patients who are unconscious after a cardiac arrest [9]. Only one randomized clinical trial evaluating the effect of different oxygen regimens used in the intensive care unit (ICU) on survival and neurological disability in patients with hypoxic ischaemic encephalopathy has been reported [11]. This trial reported that conservative oxygen therapy resulted in similar outcomes to liberal oxygen therapy in patients with hypoxic ischaemic encephalopathy but had the insufficient statistical power to detect differences in these outcomes [11].

We recently reported, in the subgroup of patients with suspected hypoxic ischaemic encephalopathy who were enrolled in the Intensive Care Unit Randomized Trial Comparing Two Approaches to OXygen therapy (ICUROX) [12], that allocation to conservative oxygen therapy was associated with a decreased risk of death and with a numerically lower rate of unfavourable neurological outcomes at 180 days [12]. It is unclear whether these findings are indicative of true benefit with conservative oxygen therapy or are accounted for by chance baseline imbalances or other confounding factors that may affect outcomes in patients who have suffered a cardiac arrest.

Accordingly, we conducted a post-hoc analysis using data from the 166 patients with suspected hypoxic ischaemic encephalopathy included in ICU-ROX [12]. Our hypothesis was that, after adjustment for baseline variables that predict outcomes in cardiac arrest patients, use of conservative oxygen therapy would decrease the probability of dying or surviving with an unfavourable neurological outcome at day 180 post-randomization compared with usual oxygen therapy.

\section{Methods}

\section{Trial design}

We conducted a post-hoc analysis in the pre-specified subgroup of patients enrolled in ICU-ROX who were considered to have possible hypoxic ischaemic encephalopathy at the time of enrollment. ICU-ROX was a 1000-participant, multicenter, prospective, parallel-group, randomised clinical trial. The protocol [13] and primary analysis [12] have been published previously. ICU-ROX was approved by the ethics committee responsible for each participating institution with approval granted to obtain specific additional data from the medical records of patients with suspected hypoxic ischaemic encephalopathy for this analysis. Written informed consent for enrollment, or consent to continue and to use patient data, was obtained from each patient or from a legal surrogate. Where a patient

\section{Take home message}

In this post-hoc analysis of patients with suspected ischaemic encephalopathy who were enrolled in ICU-ROX, conservative oxygen therapy did not result in a statistically significant decrease in death or unfavourable neurological outcome at day 180 compared with usual oxygen therapy. The potential for clinically important benefit or harm from conservative oxygen therapy in patients with suspected hypoxic ischaemic encephopathy is not excluded by these data.

died before consent to continue could be obtained, data were included if allowed by local regulations and approved by the relevant ethics committee.

\section{Patients}

Patients included in ICU-ROX were mechanically ventilated adults aged $\geq 18$ years who were expected to remain mechanically ventilated in the ICU beyond the calendar day after recruitment. Randomization was required within $2 \mathrm{~h}$ of invasive mechanical ventilation and/or noninvasive ventilation in an ICU. Otherwise, patients were considered to have missed the enrolment window.

The patients with suspected hypoxic ischaemic encephalopathy included in this analysis constituted a pre-specified subgroup that was defined pre-randomization based on whether this diagnosis was documented in the clinical records. Specific instructions were provided to research coordinators that patients admitted following cardiac arrest, should be defined as being suspected to have hypoxic ischaemic encephalopathy unless there was documentation of the patient obeying commands following the return of spontaneous circulation (ROSC), after the cardiac arrest and prior to the patient being sedated.

For this analysis, we obtained data from the medical records of patients with suspected hypoxic ischaemic encephalopathy that were not initially collected. These data comprised details pertaining to the cardiac arrest including the location of the arrest, whether the arrest was witnessed, whether there was a bystander response, the first monitored rhythm, the cause of the arrest, whether an ST elevation acute myocardial infarction (STEMI) was diagnosed, and the time until sustained ROSC [14]. We also recorded additional information about comorbidities of particular relevance to patients with cardiovascular disease. Full details of the data collected specifically for this analysis are provided in the Electronic Supplementary Material (ESM). 


\section{Randomization and study treatment}

Patients in ICU-ROX were randomly assigned to conservative oxygen therapy or usual oxygen therapy using a secure Internet-based randomization interface. The allocation sequence was generated by the study statistician using computer-generated random numbers with variable block randomization in a 1:1 ratio stratified by centre.

In both treatment groups, the monitored lower limit alarm for oxygen saturation measured by pulse oximetry $\left(\mathrm{SpO}_{2}\right)$ was set at $90 \%$ by default but an alternative lower limit could be specified if clinically indicated. If an arterial blood gas showed a partial pressure of oxygen $\left(\mathrm{PaO}_{2}\right)<60 \mathrm{mmHg}$ or an unacceptably low arterial oxygen saturation $\left(\mathrm{SaO}_{2}\right)$, the fraction of inspired oxygen $\left(\mathrm{FiO}_{2}\right)$ could be increased, irrespective of $\mathrm{SpO}_{2}$.

In patients assigned to conservative oxygen, the $\mathrm{FiO}_{2}$ was reduced as much as possible down to a minimum of 0.21 whilst still maintaining the $\mathrm{SpO}_{2}$ above the acceptable lower limit. We sought to minimize exposure to an $\mathrm{SpO}_{2} \geq 97 \%$ and hence minimize the risk of hyperoxaemia in patients assigned to conservative oxygen using an upper $\mathrm{SpO}_{2}$ alarm limit set at $97 \%$. This upper limit $\mathrm{SpO}_{2}$ alarm was used whenever supplemental oxygen was administered in the ICU.

In patients assigned to usual oxygen, no specific measures limited $\mathrm{FiO}_{2}$ or $\mathrm{SpO}_{2}$ except that the use of upper alarm limits for $\mathrm{SpO}_{2}$ was prohibited and the use of $\mathrm{FiO}_{2}$ less than 0.3 during invasive ventilation was discouraged.

Patients received their assigned oxygen therapy strategy until discharge from the ICU or 28 days from randomization, whichever occurred first. Treatment assignment was not disclosed to participants or their families.

For this analysis, we collected information about other treatments of particular relevance to cardiac arrest patients including the drugs that were administered during resuscitation, whether targeted temperature management was used, and if so, what temperature was targeted. We also recorded key neuroprognostic investigations that were performed (ESM).

\section{Outcome measures}

The primary outcome for this analysis was death or survival with an unfavourable neurological outcome at day 180 defined as an Extended Glasgow Outcome Scale (GOS-E) category of 1-4. This outcome was ascertained by contacting patients or their next of kin.

Secondary outcomes were ICU, hospital, and day 180 mortality, cause-specific mortality, survival time, ICU and hospital length of stay, ventilator-free days, and vasopressor-free days.

Cause-specific mortality was categorized using a previously described method [15]. Ventilator-free days were defined as the total number of calendar days or part calendar days of unassisted breathing during the first 28 days after randomization, all patients who died by day 28 were assigned zero ventilator-free days [16]. Vasopressor-free days were defined in an analogous fashion.

\section{Statistical Analysis}

The statistical analysis plan for ICU-ROX was reported before enrolment was completed [13]. Whilst not prespecified, the analysis reported here was conducted in accordance with the original analysis plan. We chose death or survival with an unfavourable neurological outcome at day 180 as the primary outcome as the most relevant outcome for patients with hypoxic ischaemic encephalopathy. Analyses were conducted on an intention-to-treat basis. We defined the intention-to-treat population as all enrolled patients except those who withdrew consent for use of data. We conducted a posthoc best/worst analysis to account for missing primary outcome data.

For the primary analysis of death or survival with an unfavourable neurological outcome at day 180, we used an unadjusted Fisher's exact test for equal proportions, and report frequency (percentage) per treatment group with an absolute difference, odds ratio, and associated 95\% confidence intervals. Other dichotomous endpoints were analysed in the same fashion. We conducted a sensitivity analysis comparing GOS-E on the ordinal scale. Because there was insufficient proportionality between categories to enable ordinal logical regression, this analysis was undertaken non-parametrically. We compared survival times using log-rank tests and present these as Kaplan-Meier curves and used a Cox proportional-hazards model to calculate hazard ratios for survival. For continuous secondary outcomes, we used a Wilcoxon rank-sum test with differences between medians calculated using quantile regression employing a simplex algorithm with $95 \%$ confidence intervals $(\mathrm{CI})$ calculated using the inversion method [17].

Hierarchical multivariable analyses were performed for all binary outcomes using logistic regression and for survival using a Cox proportional-hazards model. These analyses incorporated adjustment for the independent covariates of age, cardiac arrest location outside the hospital, shockable first monitored rhythm, time to ROSC, whether there was a medical cause for arrest, and whether the patient had a STEMI. A medical cause of cardiac arrest included cases in which the cause of the cardiac arrest was presumed to be cardiac, other medical cause (eg, anaphylaxis, asthma, GI bleed), and cases in which no obvious cause of the cardiac arrest was identified. These analyses were undertaken with patients nested in site and 
site treated as a random variable. Covariates were prespecified based on their known associations with neurological outcome in cardiac arrest patients [14].

Analyses for variables that were measured repeatedly such as time-weighted $\mathrm{PaO}_{2}$ were performed using mixed linear modelling (with each patient treated as a random effect) fitting main effect for treatment and time and an interaction between treatment and time to determine if groups behaved differently over time.

Analyses were conducted using SAS statistical software, version 9.4 (SAS Institute). Statistical significance was determined using a two-sided hypothesis test with an alpha of 0.05 .

\section{Results}

Patient characteristics

From September 2015 through May 2018, we enrolled 1000 patients into ICU-ROX from 21 ICUs in Australia and New Zealand. There were 965 patients in the intention-to-treat population. A total of 166 patients were suspected to have hypoxic ischaemic encephalopathy at baseline with $87(52.4 \%)$ of these randomized to conservative oxygen therapy. Data related to neurological outcomes at 6 months were missing for 16 participants (Fig. 1). The study groups had similar characteristics at baseline (Table 1) and the drugs given during resuscitation were similar (Table 2).

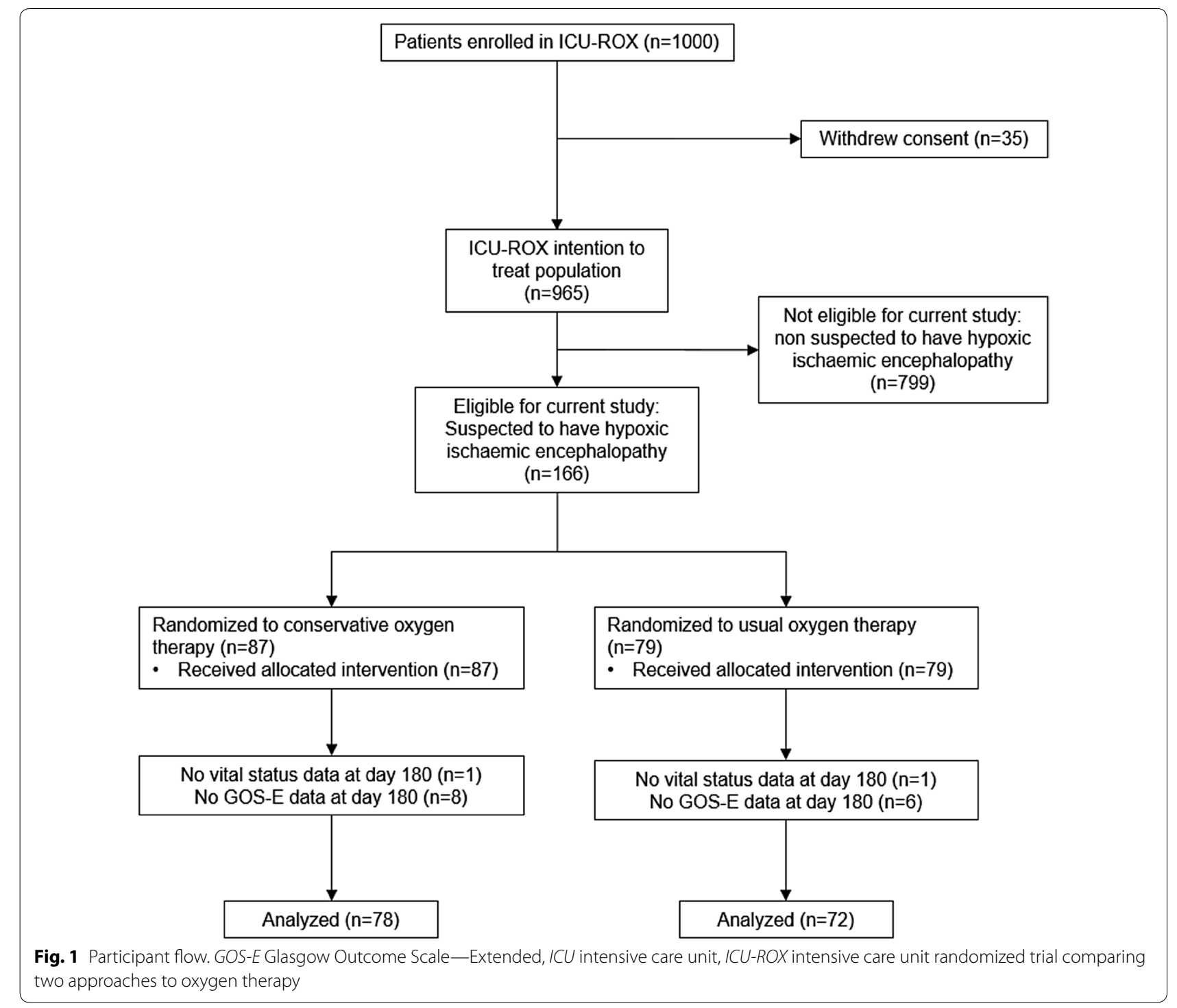


Table 1 Characteristics of the patients at baseline

\begin{tabular}{|c|c|c|c|}
\hline Characteristic & $\begin{array}{l}\text { Conservative oxygen } \\
(n=87)\end{array}$ & $\begin{array}{l}\text { Usual oxygen } \\
(n=79)\end{array}$ & $P$ value \\
\hline Age-year, mean (SD) & $62.3 \pm 14.8$ & $60.6 \pm 16.1$ & 0.49 \\
\hline Male sex-no. (\%) & $66(75.9 \%)$ & $62(78.5 \%)$ & 0.69 \\
\hline \multicolumn{4}{|l|}{ Comorbid conditions - no. (\%) } \\
\hline Hypertension & $33(37.9 \%)$ & $24(30.4 \%)$ & 0.31 \\
\hline Diabetes & $24(27.6 \%)$ & $18(22.8 \%)$ & 0.48 \\
\hline Ischaemic heart disease & $18(20.7 \%)$ & $23(29.1 \%)$ & 0.21 \\
\hline Asthma or COPD & $17(19.5 \%)$ & $15(19 \%)$ & 0.93 \\
\hline Previous myocardial infarction & $10(11.5 \%)$ & $16(20.3 \%)$ & 0.12 \\
\hline Previous cardiac arrhythmia & $14(16.1 \%)$ & $8(10.1 \%)$ & 0.26 \\
\hline Percutaneous coronary intervention & $8(9.2 \%)$ & $10(12.7 \%)$ & 0.47 \\
\hline Congestive heart failure & $10(11.5 \%)$ & $6(7.6 \%)$ & 0.4 \\
\hline Previous CABG & $10(11.5 \%)$ & $5(6.3 \%)$ & 0.25 \\
\hline Previous TIA or stroke & $4(4.6 \%)$ & $7(8.9 \%)$ & 0.27 \\
\hline \multicolumn{4}{|l|}{ Cardiac arrest location—no. (\%) } \\
\hline Emergency department & $3(3.4 \%)$ & $6(7.6 \%)$ & 0.24 \\
\hline Hospital ward & $5(5.7 \%)$ & $3(3.8 \%)$ & 0.56 \\
\hline $\mathrm{ICU}$ & $1(1.1 \%)$ & $0(0 \%)$ & 1.00 \\
\hline Operating theatre & $0(0 \%)$ & $1(1.3 \%)$ & 0.48 \\
\hline Other location in hospital & $1(1.1 \%)$ & $3(3.8 \%)$ & 0.35 \\
\hline Home/residence & $33(37.9 \%)$ & $32(40.5 \%)$ & 0.73 \\
\hline Assisted living/nursing home & $1(1.1 \%)$ & $2(2.5 \%)$ & 0.61 \\
\hline Other location (not in hospital) & $43(49.4 \%)$ & $32(40.5 \%)$ & 0.25 \\
\hline Witnessed arrest ${ }^{\mathrm{a}}$ —no. (\%) & $72(82.8 \%)$ & $61(77.2 \%)$ & 0.37 \\
\hline Bystander response-no. (\%) & $65(74.7 \%)$ & $56(70.9 \%)$ & 0.58 \\
\hline First monitored rhythm VF, VT, or AED shockable-no. (\%) & $58(66.7 \%)$ & $46(58.2 \%)$ & 0.26 \\
\hline Response time-mins, mean (SD); range & $7.3 \pm 6.3$ & $5.0 \pm 4.2$ & 0.01 \\
\hline Time to defibrillation—mins, mean (SD) & $9.7 \pm 7$ & $9.0 \pm 5.2$ & 0.56 \\
\hline Time until sustained ROSC - mins, mean (SD); range & $26.5 \pm 17.82-84$ & $25.4 \pm 14.7 ; 2-66$ & 0.69 \\
\hline \multicolumn{4}{|l|}{ Cause of arrest—no. (\%) } \\
\hline Medical & $84(96.6 \%)$ & 71 (89.9\%) & 0.08 \\
\hline Asphyxia & $3(3.4 \%)$ & $4(5.1 \%)$ & 0.71 \\
\hline Drug overdose & $0(0 \%)$ & $2(2.5 \%)$ & 0.23 \\
\hline Drowning & $0(0 \%)$ & $1(1.3 \%)$ & 0.48 \\
\hline Traumatic & $0(0 \%)$ & $1(1.3 \%)$ & 0.48 \\
\hline Presence of STEMI—no./N (\%) & 23/86 (26.7\%) & 29/77 (37.7\%) & 0.14 \\
\hline \multicolumn{4}{|l|}{ Physiology ${ }^{b}$} \\
\hline Respiratory rate-breaths per min & $16.1 \pm 3.5$ & $16.4 \pm 4.2$ & 0.62 \\
\hline $\mathrm{SpO}_{2}-\%$ & $98[96-100]$ & $96[95-99]$ & 0.04 \\
\hline $\mathrm{PaO}_{2}$ - mmHg; median [IQR] & $107[86.8-172]$ & $94.5[82.5-141]$ & 0.39 \\
\hline $\mathrm{PaCO}_{2}-\mathrm{mmHg}$ & $49.4 \pm 13.8$ & $47.4 \pm 13.4$ & 0.37 \\
\hline \multicolumn{4}{|l|}{ Physiological support } \\
\hline $\mathrm{FIO}_{2}$ & $0.64 \pm 0.23$ & $0.64 \pm 0.24$ & 0.91 \\
\hline $\mathrm{PEEP}-\mathrm{CmH}_{2} \mathrm{O}$; median $[\mathrm{IQR}]$ & $5[5-10]$ & $8[5-10]$ & 0.13 \\
\hline Inotropic/vasopressor support—no. (\%) & $33(37.9 \%)$ & $34(43 \%)$ & 0.5 \\
\hline Time from ICU admission to randomisation—hours; median [IQR] & $1.25[0.62-1.7]$ & $1.1[0.7-1.78]$ & 0.84 \\
\hline
\end{tabular}

Plus-minus values are expressed as mean $\pm \mathrm{SD}$

$A E D$ automated external defibrillator, COPD chronic obstructive pulmonary disease, $I C U$ intensive care unit, $O R$ operating room, $V F$ ventricular fibrillation, $V T$ ventricular tachycardia, $\mathrm{ROSC}$ return of spontaneous circulation, $\mathrm{SpO}_{2}$ arterial oxygen saturation on pulse oximetry, $\mathrm{PaO}_{2}$ arterial partial pressure of oxygen, FiO fraction of inspired oxygen, $\mathrm{PaCO}_{2}$ arterial partial pressure of carbon dioxide, $P E E P$ positive end expiratory pressure

a A witnessed arrest was defined as one that was seen or heard by another person or was monitored

b Respiratory rate and $\mathrm{SpO}_{2}$ data were available for 86 conservative oxygen patients and 78 usual oxygen patients; $\mathrm{PaO}_{2}$ and $\mathrm{PaCO} \mathrm{C}_{2}$ data were available for 79 conservative oxygen patients and 71 usual oxygen patients 
Table 2 Treatment and prognostication

\begin{tabular}{|c|c|c|c|}
\hline Characteristics & Conservative oxygen $(n=87)$ & Usual oxygen $(n=79)$ & $P$ value \\
\hline \multicolumn{4}{|l|}{ Pre-randomisation treatment } \\
\hline \multicolumn{4}{|l|}{ Drugs given during resuscitation-no. (\%) } \\
\hline Adrenaline & $60(69 \%)$ & $60(75.9 \%)$ & 0.32 \\
\hline Amiodarone & $24(27.6 \%)$ & $24(30.4 \%)$ & 0.69 \\
\hline Vasopressin & $0(0 \%)$ & $0(0 \%)$ & 1.00 \\
\hline None given & $24(27.6 \%)$ & $17(21.5 \%)$ & 0.37 \\
\hline Unknown & $2(2.3 \%)$ & $1(1.3 \%)$ & 1.00 \\
\hline \multicolumn{4}{|l|}{ Post-randomisation oxygen therapy } \\
\hline Proportion of hours $\mathrm{SpO}_{2} \geq 97 \%$ & $0.391(0.254)$ & $0.529(0.257)$ & 0.001 \\
\hline Number of hours $\mathrm{SpO}_{2} \geq 97 \%$ & $26[13-45]$ & $35[19-70]$ & 0.05 \\
\hline Proportion of hours $\mathrm{SpO}_{2}<88 \%$ & $0[0-0.02]$ & $0[0-0.01]$ & 0.37 \\
\hline Number of hours $\mathrm{SpO}_{2}<88 \%$ & $0[0-2]$ & $0[0-1]$ & 0.4 \\
\hline $\begin{array}{l}\text { Proportion of patients with at least one } \mathrm{PaO}_{2} \text { recording less } \\
\text { than } 60 \mathrm{mmHg}\end{array}$ & $31(87 \%)$ & $15 / 79(19 \%)$ & 0.02 \\
\hline $\begin{array}{l}\text { Proportion of patients with at least one } \mathrm{PaO}_{2} \text { recording } \\
\text { greater than } 100 \mathrm{mmHg}\end{array}$ & $51(59 \%)$ & $60(76 \%)$ & 0.02 \\
\hline Proportion of hours $\mathrm{FiO}_{2} 0.21$ & $0.37[0.08-0.61]$ & $0[0-0.12]$ & $<0.0001$ \\
\hline Number of hours $\mathrm{FiO}_{2} 0.21$ & $25[8-43]$ & $0[0-6]$ & $<0.0001$ \\
\hline \multicolumn{4}{|l|}{ Other post-randomisation treatment } \\
\hline Targeted temperature management—no. (\%) & $72(82.8 \%)$ & $65(82.3 \%)$ & 0.94 \\
\hline Target $32-34{ }^{\circ} \mathrm{C}-n / N(\%)$ & $3 / 72(4.2 \%)$ & $4 / 65(6.2 \%)$ & 0.79 \\
\hline Target $36^{\circ} \mathrm{C}-n / N(\%)$ & $51 / 72(70.8 \%)$ & $43 / 65(66.2 \%)$ & \\
\hline Other target-n/N (\%) & $18 / 72(25.0 \%)$ & $18 / 65(27.7 \%)$ & \\
\hline \multicolumn{4}{|l|}{ Neuroprognostic tests performed ${ }^{\mathrm{a}}-$ no. (\%) } \\
\hline Somatosensory evoked potentials (SSEPs) & $6(7 \%)$ & $8(10.1 \%)$ & 0.45 \\
\hline Neurone specific enolase (NSE) & $0(0 \%)$ & $0(0 \%)$ & 1.00 \\
\hline Electroencephalogram (EEG) & $8(9.2 \%)$ & $14(17.7 \%)$ & 0.11 \\
\hline CT brain & $39(44.8 \%)$ & $26(32.9 \%)$ & 0.12 \\
\hline MRI brain & $5(5.7 \%)$ & $10(12.7 \%)$ & 0.12 \\
\hline
\end{tabular}

a SSEP and NSE data were available for 86 conservative oxygen patients and 78 usual oxygen patients

\section{Oxygenation and process of care measures}

Patients allocated to conservative oxygen spent less time in the ICU with an $\mathrm{SpO}_{2} \geq 97 \%$ (26 h [interquartile range (IQR) 13-45 vs. $35 \mathrm{~h}$ [IQR 19-70], absolute difference, - $9 \mathrm{~h}$; $95 \% \mathrm{CI}-21.4$ to 3.4 ), and more time receiving an $\mathrm{FIO}_{2}$ of 0.21 than patients allocated to usual oxygen (25 h [IQR 8-43] vs. $0 \mathrm{~h}$ [IQR 0-6], absolute difference, 25.0 h; 95\% CI 18.7-31.1) (Table 2). The time-weighted $\mathrm{PaO}_{2}$ over the first 10 days of mechanical ventilation was $84 \mathrm{mmHg}(95 \% \mathrm{CI} 78-90 \mathrm{mmHg}$ ) for the conservative oxygen therapy group and $88 \mathrm{mmHg}$ (95\% CI 82-94 $\mathrm{mmHg}$ ) for the usual oxygen therapy group; difference -4 (95\% CI -12.2 to $4.2 \mathrm{mmHg}) ; P=0.33$ (Fig. 2). Highest and lowest daily $\mathrm{PaO}_{2}$ during the first 28 mechanical ventilation days are shown in Fig. 2. Patients allocated to conservative oxygen therapy were significantly more likely to experience episodes of hypoxaemia $\left(\mathrm{PaO}_{2}<60 \mathrm{mmHg}\right)$ and significantly less likely to experience episodes of hyperoxaemia $\left(\mathrm{PaO}_{2}>100 \mathrm{mmHg}\right)$ than patients allocated to usual oxygen therapy (Table 2). Temperature management strategies used and neuroprognostic tests performed were similar by treatment group (Table 2). The mean $\mathrm{FiO}_{2}$ during the first 10 mechanical ventilation days was statistically significantly lower in the conservative oxygen group (Fig S1, ESM). The timeweight daily $\mathrm{PaCO}_{2}$ was similar by treatment group (Fig $\mathrm{S} 2, \mathrm{ESM})$. The mean PEEP values by treatment group are shown in Fig S3 (ESM).

\section{Primary outcome}

A total of 43 of 78 patients (55.1\%) assigned to conservative oxygen therapy and 49 of 72 patients $(68.1 \%)$ assigned to usual oxygen therapy died or survived with an unfavourable neurological outcome at day 180; absolute difference; - 12.9 percentage points; $95 \%$ CI - 28.3 percentage points to 2.5 percentage points; odds ratio 0.58 ; $95 \%$ CI $0.3-1.12 ; P=0.14$; adjusted odds ratio 0.54 ; 95\% CI 0.23-1.26; $P=0.15$ ) (Table 3, Fig. 3). Analyses 


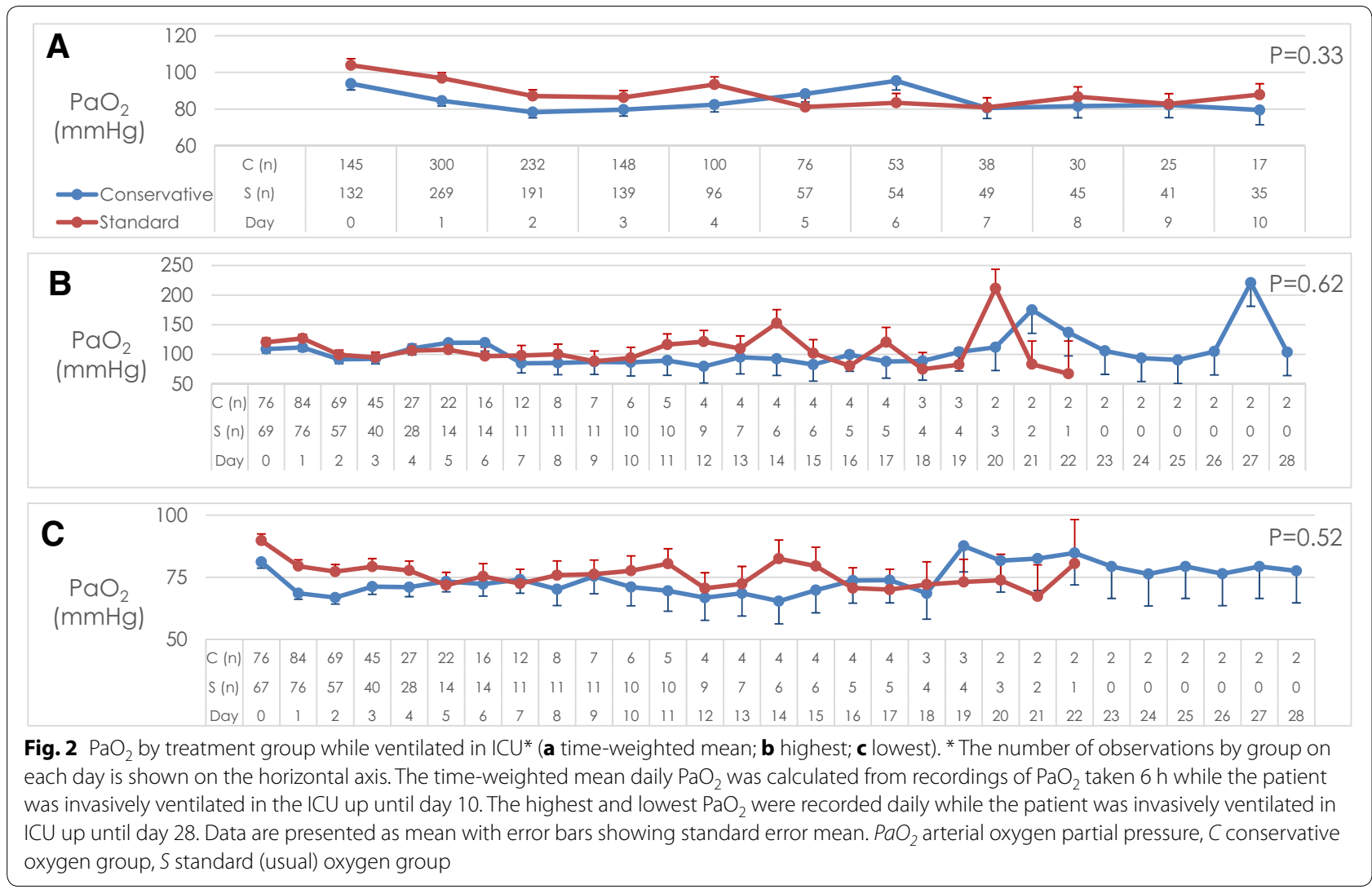

accounting for missing data are shown in the ESM and indicate even greater imprecision in treatment estimates than the primary analyses. A survival curve focusing on the first 10 days following randomization is shown in Fig. S4 (ESM). In a sensitivity analysis considering the entire ordinal scale, the median GOS-E score was statistically significantly better with conservative oxygen therapy arm compared to usual oxygen therapy 4 , IQR $1-7$ vs. 1 , IQR $1-6 ; P=0.03$.

\section{Secondary Outcomes}

A total of 37 of 86 patients (43\%) assigned to conservative oxygen therapy and 46 of 78 (59\%) assigned to usual oxygen therapy had died by day 180; absolute difference; - 16 percentage points; $95 \% \mathrm{CI}-31.1$ percentage points to -0.8 percentage points; odds ratio 0.53 ; $95 \%$ CI $0.28-$ $0.98 ; P=0.04$; adjusted odds ratio 0.56 ; $95 \%$ CI $0.25-1.23$; $P=0.15$. ICU mortality and in-hospital mortality were not significantly different by treatment groups (Table 3 ). Brain damage was the commonest proximate cause of death and accounted for a similar proportion of deaths in the two treatment groups (Table 3).

ICU and hospital length of stay were similar by treatment group; however, vasopressor-free days and ventilator-free days were statistically significantly higher in the conservative oxygen therapy group. Duration of ventilation among those patients who survived for 28 days or more did not differ significantly by treatment group. However, the duration of vasopressor support among those patients who survived 28 days or more was 1 day longer (95\% CI 0.03-1.97) among those allocated to conservative oxygen therapy (Table 3 ).

\section{Discussion}

In this post-hoc analysis of patients with suspected hypoxic ischaemic encephalopathy from the ICU-ROX trial [12], conservative oxygen therapy was not associated with a statistically significant reduction in death or unfavourable neurological outcomes at day 180 compared with usual oxygen therapy when the GOS-E was dichotomized into favourable and unfavourable outcome categories. While an analysis across the entire ordinal GOS-E favoured conservative oxygen therapy and the point estimate for the treatment effect favoured conservative oxygen therapy in the dichomotised analysis, the 95\% confidence interval in this latter analysis was wide. Moreover, in an analysis adjusting for baseline covariates that predict mortality in cardiac arrest patients, the confidence interval was sufficiently wide that it encompassed 
Table 3 Primary outcome and key secondary outcomes

\begin{tabular}{|c|c|c|c|c|c|c|}
\hline & \multirow[t]{2}{*}{$\begin{array}{l}\text { Conservative oxygen } \\
(n=87)\end{array}$} & \multirow[t]{2}{*}{$\begin{array}{l}\text { Usual oxygen } \\
(n=79)\end{array}$} & \multicolumn{4}{|l|}{$\begin{array}{l}\text { Estimate }^{a}(95 \% \mathrm{Cl}) \\
\text { Odds ratio }\end{array}$} \\
\hline & & & Unadjusted & $P$ value & Adjusted $^{\mathbf{b}}$ & $P$ value \\
\hline $\begin{array}{l}\text { Unfavourable neuro- } \\
\text { logical outcome at } \\
\text { day } 180-n / N(\%)\end{array}$ & $43 / 78(55.1 \%)$ & 49/72 (68.1\%) & $0.58(0.3-1.12)$ & 0.10 & $0.54(0.23-1.26)$ & 0.15 \\
\hline $\begin{array}{l}\text { Day } 180 \text { mortality- } \\
n / N(\%)\end{array}$ & $37 / 86(43 \%)$ & $46 / 78(59 \%)$ & $0.53(0.28-0.98)$ & 0.04 & $0.56(0.25-1.23)$ & 0.15 \\
\hline Died in ICU—n (\%) & $31(35.6 \%)$ & $37(46.8 \%)$ & $0.63(0.34-1.17)$ & 0.14 & $0.68(0.31-1.48)$ & 0.33 \\
\hline \multirow[t]{2}{*}{$\begin{array}{l}\text { Died in hospital—n } \\
(\%)\end{array}$} & $37(42.5 \%)$ & $43(54.4 \%)$ & $0.62(0.34-1.14)$ & 0.13 & $0.65(0.3-1.42)$ & 0.28 \\
\hline & & & \multicolumn{2}{|c|}{$\begin{array}{l}\text { Difference in medians } P \text { value } \\
(95 \% \mathrm{Cl})\end{array}$} & & \\
\hline $\begin{array}{l}\text { ICU length of stay } \\
\text { (days)—-median [IQR] }\end{array}$ & $3.01[2.03-5.91]$ & $3[1.75-5.67]$ & $0.01(-1.21$ to 1.23$)$ & 0.99 & & \\
\hline $\begin{array}{l}\text { Hospital length of stay } \\
\text { (days)—-median [IQR] }\end{array}$ & $8.72[3.89-17.6]$ & $6.49[2.31-14.2]$ & $2.23(-1.04$ to 5.5$)$ & 0.18 & & \\
\hline $\begin{array}{l}\text { Vasopressor-free } \\
\text { days—median [IQR] }\end{array}$ & $23[0-26]$ & 0 [0-25] & $23(12.43-33.57)$ & $<0.001$ & & \\
\hline $\begin{array}{l}\text { Duration of vasopres- } \\
\text { sors (days, survivors } \\
\text { to day 28)-median } \\
\text { [IQR] }\end{array}$ & $3[1-4], N=51$ & $2.5[1.5-4] ; N=36$ & $1(0.03-1.97)$ & 0.04 & & \\
\hline $\begin{array}{l}\text { Ventilator-free days- } \\
\text { median [IQR] }\end{array}$ & $21.1[0-26.1]$ & $0[0-26]$ & $21.08(10.43-31.73)$ & $<0.001$ & & \\
\hline $\begin{array}{l}\text { Duration of ventila- } \\
\text { tion (hours, survivors } \\
\text { to day } 28 \text { only) - } \\
\text { median [IQR] }\end{array}$ & $51[27-92] ; N=51$ & $45.5[23-114] ; N=36$ & $5.0(-27.3$ to 37.3$)$ & 0.52 & & \\
\hline \multicolumn{3}{|c|}{ Cause-specific mortality—n/N (\%) } & & $P$ value $^{\mathrm{d}}=0.87$ & & \\
\hline Arrhythmia & $8 / 37(21.6 \%)$ & $7 / 46(15.2 \%)$ & & & & \\
\hline Brain death & $3 / 37(8.1 \%)$ & $2 / 46(4.3 \%)$ & & & & \\
\hline $\begin{array}{l}\text { Brain damage (not } \\
\text { brain death) }\end{array}$ & $15 / 37(40.5 \%)$ & $20 / 46(43.5 \%)$ & & & & \\
\hline Cardiogenic shock & 9/37 (24.3\%) & $12 / 46(26.1 \%)$ & & & & \\
\hline Distributive shock & $1 / 37(2.7 \%)$ & $1 / 46(2.2 \%)$ & & & & \\
\hline $\begin{array}{l}\text { Hypoxic respiratory } \\
\text { failure }\end{array}$ & $1 / 37(2.7 \%)$ & $3 / 46(6.5 \%)$ & & & & \\
\hline Metabolic & $0 / 37(0 \%)$ & $1 / 46(2.2 \%)$ & & & & \\
\hline
\end{tabular}

IQR interquartile range, $\mathrm{Cl}$ confidence interval

a The widths of the confidence intervals for secondary analyses have not been adjusted for multiplicity and the intervals should not be used to infer definite differences between the groups

b Adjusted for age, cardiac arrest location outside the hospital, shockable first monitored rhythm, time to ROSC, whether there was a medical cause for arrest, and whether the patient had a STEMI. These analyses were undertaken with patients nested in site and site treated as a random variable

c All differences in medians $[95 \% \mathrm{Cl}]$ were calculated using quantile regression

d $P$ value for cause-specific mortality calculated using Chi-square test

both clinically important benefit and clinically important harm. Although day 180 mortality was statistically significantly reduced in the conservative group in the originally reported unadjusted analysis [12], this finding was not robust to the adjustment for differences in baseline covariates reported in the current analysis. There was no statistically significant difference in mortality at other time points and, causes of death did not differ significantly by treatment allocation. We did note statistically significant increases in both ventilator-free days and vasopressor-free days among patients assigned to conservative oxygen therapy.

The largest prior randomized clinical trial evaluating oxygen therapy in patients with suspected hypoxic 


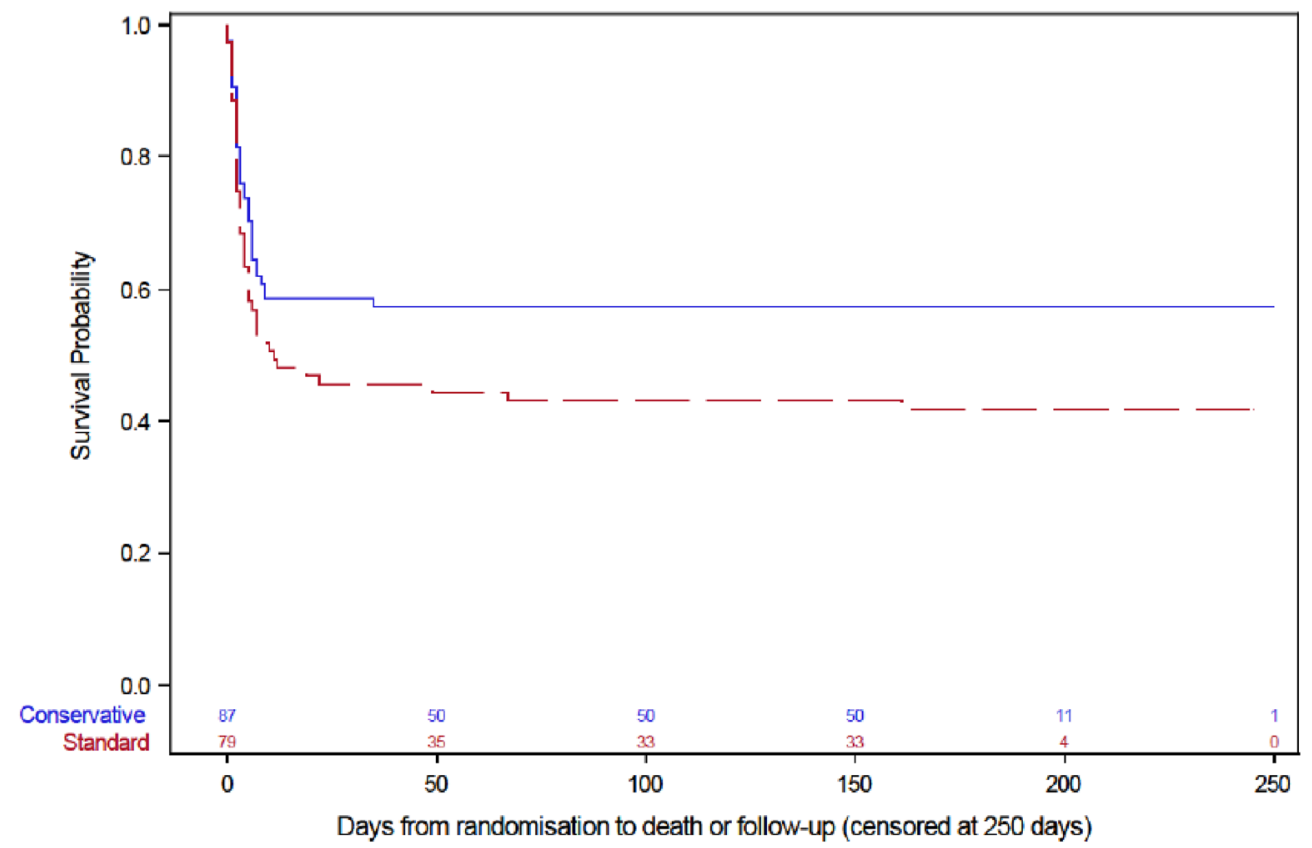

Treatment_group C Conservative — - Standard

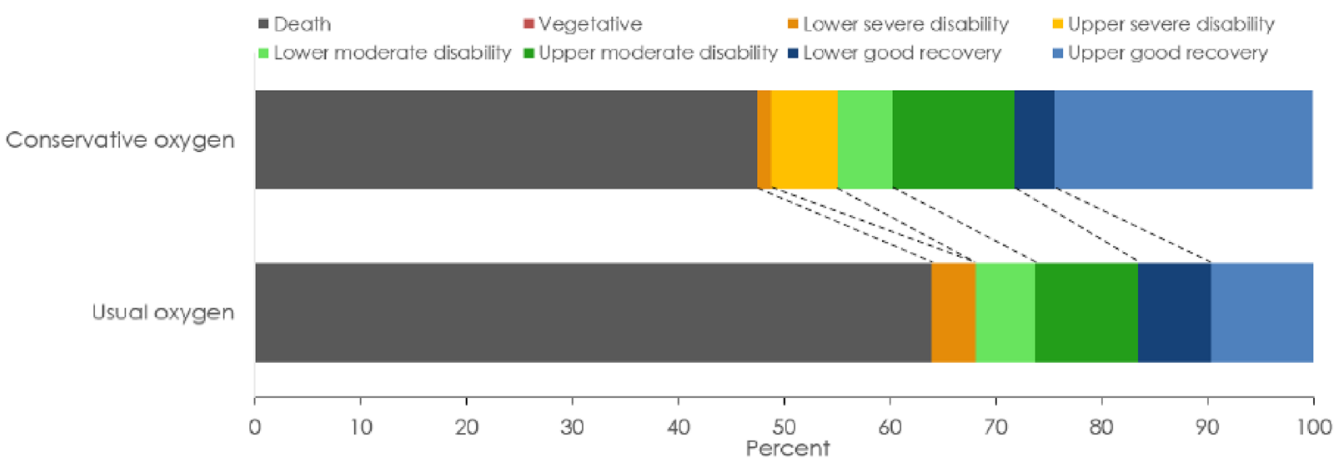

Fig. 3 Kaplan-Meier estimates of the probability of survival and Glasgow Outcome Scale Extended (GOS-E) categories for patients with suspected hypoxic ischemic encephalopathy*. *Adapted from N Engl J Med, ICU-ROX investigators, Conservative Oxygen Therapy During Mechanical Ventilation in the ICU, 382: 989-998 Copyright @ 2020 Massachusetts Medical Society. Reprinted with permission. The number of observations in the Kaplan-Meier analysis is shown by treatment group on the horizontal axis. Adjusted hazard ratio, $0.67(95 \% \mathrm{Cl} 0.43-1.03), P=0.20$. Adjusted for age, cardiac arrest location outside hospital, shockable first monitored rhythm, time to ROSC, whether there was a medical cause for arrest, and whether the patient had a STEMI. Analysis was undertaken with patients nested in site and site treated as a random variable. GOS-E Glasgow Outcome Scale, ROSC return of spontaneous circulation, STEMI ST elevation acute myocardial infarction

ischaemic encephalopathy was $2^{3}$ factorial trial from the COMACARE study group [11]. In this trial, 123 patients resuscitated from out-of-hospital cardiac arrest were randomized to low-normal or high-normal $\mathrm{PaCO}_{2}$ and to normoxia [arterial oxygen tension $\left.\left(\mathrm{PaO}_{2}\right) 75-112.5 \mathrm{mmHg}\right]$ or moderate hyperoxia $\left(\mathrm{PaO}_{2}\right.$ 150-187.5 $\mathrm{mmHg}$ ) and to low-normal or high-normal mean arterial pressure for $36 \mathrm{~h}$ in the intensive care unit [11]. An important difference between the COMACARE trial and ICU-ROX was that the COMACARE trial systematically targeted moderate hyperoxaemia in the control arm. In contrast, in ICU-ROX, the control arm was usual care and no attempt was made to target hyperoxaemia. In ICU-ROX, allocation to conservative oxygen therapy was associated with a statistically significant reduction in the proportion of hours that were spent with an $\mathrm{SpO}_{2}$ of $\geq 97 \%$. However, the magnitude of between-group differences in $\mathrm{PaO}_{2}$ values in the subgroup of ICU-ROX patients with hypoxic ischaemic encephalopathy was generally smaller than the difference 
between groups in the COMACARE trial. Despite these differences, our findings are broadly consistent with those of the COMACARE trial where there was no statistically significant effect of oxygen regimens on 30-day mortality rates or the proportion of patients with a good neurological outcome at 6 months but point estimates favoured normoxia. Our data do not preclude the possibility that oxygen regimens that target higher oxygen levels than those used in usual ICU practice are harmful. Patients allocated to conservative oxygen therapy were more likely to be exposed to hypoxaemia. The clinical relevance of the difference in oxygen exposure between groups that we observed, and of the increased frequency of hypoxaemia that we observed in patients allocated to conservative oxygen therapy, can only be established through the conduct of larger randomized clinical trials. If the magnitude of treatment effects on day 180 mortality and unfavourable neurological outcomes suggested by the point estimates observed in this study were confirmed in a larger trial, then the magnitude of separation in oxygen exposure we observed would clearly be important and conservative oxygen therapy would be appropriate to implement despite the associated risk of exposure to hypoxaemia associated with this therapy.

We sought to evaluate whether the difference in day 180 mortality reported in the ICU-ROX trial in patients with suspected with hypoxic ischaemic encephalopathy might be due to chance imbalances between treatment groups. Accordingly, for this study we collected a wide range of data of particular relevance to cardiac arrest patients including arrest details, important cointerventions like temperature management, and details of neuroprognostic tests performed. Although these were generally similar by treatment group, adjustment for pre-specified baseline covariates [14] resulted in a reduction in the precision of our treatment effect estimates. Our study has a number of limitations. The size of our sample precluded us adjusting for all potentially important baseline variables. We cannot exclude the possibility that usual care patients were sicker as evidenced by their slightly lower average $\mathrm{SpO}_{2}$ and slightly more frequent use of adrenaline during resuscitation. It is also possible that there were other imbalances between groups in important variables that we did not measure such as the number of shocks performed, airway control used, or in the use of mechanical compression devices. In addition, differences in outcomes between treatment groups may simply have occurred due to the play of chance. Although the use of neuroprognostic tests was similar by treatment group, the lack of standardization of decisions related to the withdrawal of active treatment, is a potential source of bias in this study. There were 16 patients where data relating to neurological outcomes at 180 days were not available. These data may not be missing at random because patients with better (or worse) outcomes might be harder to contact. We did not collect information related to oxygen delivery such as lactate and central venous oxygen saturation. Although we did not observe a significant increase in hypoxaemia among patients allocated to conservative oxygen therapy, cardiogenic shock and arrhythmias were common causes of death, and the risk of these could potentially be affected by oxygen delivery.

This study includes the largest sample of patients in which oxygen therapy has been evaluated in hypoxic ischaemic encephalopathy in a randomized clinical trial. In this analysis conservative oxygen therapy was not associated with a statistically significant reduction in death or survival with the unfavourable neurological outcome at day 180 . The potential for clinically important benefit or harm from conservative oxygen therapy in patients with suspected hypoxic ischaemic encephopathy is not excluded by these data. Our data can be used to inform the design of future trials and indicate that a sample size of 586 would provide $90 \%$ power to detect an absolute difference in the proportion of patients with an unfavourable neurological outcome at day 180 of 13 percentage points, based on a control event rate of $68.1 \%$, and using a two-tailed test. Although some clinicians may choose to implement [18] conservative oxygen therapy in this patient population based on the consistency of animal data [3], some observational data [4-8], and trends towards benefits from existing randomized controlled trials $[6,12]$, further larger trials are needed to provide data that are sufficiently robust to generate clear clinical practice recommendations [19].

\section{Electronic supplementary material}

The online version of this article (https://doi.org/10.1007/s00134-020-06196-y) contains supplementary material, which is available to authorized users.

\begin{abstract}
Author details
${ }^{1}$ Medical Research Institute of New Zealand, Wellington, New Zealand. 2 Intensive Care Unit, Wellington Hospital, Private Bag 7902, Wellington, New Zealand. ${ }^{3}$ Australian and New Zealand Intensive Care Research Centre, Monash University, Melbourne, VIC, Australia. ${ }^{4}$ Intensive Care Unit, Austin Hospital, Heidelberg, VIC, Australia. ${ }^{5}$ University of Melbourne, Parkville, VIC, Australia. ${ }^{6}$ Intensive Care Unit, Royal Melbourne Hospital, Parkville, VIC, Australia. ${ }^{7}$ Division of Critical Care Division, The George Institute for Global Health, University of New South Wales, Sydney, NSW, Australia. ${ }^{8}$ Malcolm Fisher Department of Intensive Care Medicine, Royal North Shore Hospital, St Leonards, NSW, Australia. ${ }^{9}$ Intensive Care Unit, Hawkes Bay Hospital, Hastings, New Zealand. ${ }^{10}$ Intensive Care Unit, Fiona Stanley Hospital, Murdoch, WA, Australia. ${ }^{11}$ Department of Critical Care Medicine, Auckland City Hospital, Auckland, New Zealand. ${ }^{12}$ Cardiothoracic and Vascular Intensive Care Unit, Auckland City Hospital, Auckland, New Zealand. ${ }^{13}$ Intensive Care Unit, John Hunter Hospital, New Lambton Heights, NSW, Australia. ${ }^{14}$ School of Medicine and Public Health, University of Newcastle, Newcastle, Australia.
\end{abstract}

Acknowledgements

COORDINATING CENTERS: Medical Research Institute of New Zealand, Wellington, New Zealand: Tanya Baker, Sally Hurford, Mary La Pine, Diane Mackle, Carla 
McInnes, Leanlove Navarra, Allison Pritchard, Raulle Sol Cruz and Anne Turner; Australian and New Zealand Intensive Care Research Centre, Melbourne, Australia: Tessa Broadley, Victoria King, Dana Lee, Natalie Linke, Liadain Reid and Lynnette Murray. ICU-ROX INVESTIGATORS AND SITES: New Zealand Auckland City Hospital, Cardiothoracic and Vascular ICU: Aimee Blakemore, Magdalena Butler, Keri-Anne Cowdrey, Eileen Gilder, Jane Hallion, Stephanie Long, Shay McGuinness, Philippa Neal, Rachael Parke and Samantha Wallace; Auckland City Hospital, Department of Critical Care Medicine: Yan Chen, Colin McArthur, Rachael McConnochie, Lynette Newby and Catherine Simmonds; Christchurch Hospital: David Bowie, Brandon Burke, David Closey, Rosalind Crombie, Neil Davidson, Andrew Greer, Seton Henderson, Louise Hitchings, David Knight, Jan Mehrtens, Kate Miller, Emmeline Minto, Stacey Morgan, Anna Morris, Kim Parker, Jay Ritzema-Carter, Jessica Roberts, Christian Sahl, Geoffrey Shaw and Katherine Townend; Hawke's Bay Hospital: Llesley Chadwick, Debra Chalmers, Ross Freebairn, Michael Park, Penelope Park and Christine Rolls; Hutt Hospital: Carmel Chapman and Andrew Stapleton; Middlemore Hospital: Jefferson Aguila, Anisha Dias, Alex Kazemi, Vivian Lai, Rima Song and Tony Williams; North Shore Hospital: Sheila Caniba, Maud Carpenter, Rica Dagooc, Danielle Hacking and Ywain Lawrey; Rotorua Hospital: Ulrike Buehner and Erin Williams; Taranaki Base Hospital: Jonathan Albrett, Carolyn Jackson and Peter Marko; Wellington Regional Hospital: Ben Barry, Nina Beehre, Dick Dinsdale, Samantha Edney, Frances Fitzjohn, Peter Hicks, Georgia Hill, Anna Hunt, Harriet Judd, Charlotte Latimer-Bell, Cassie Lawrence, Eden Lesona, Agnes McKay-Vucago, Leanlove Navarra, Chris Poynter, Alex Psirides, Yvonne Robertson, Hannah Smellie, Raulle Sol Cruz, Shawn Sturland, Bob Ure and Paul Young. Australia Alfred Hospital: Jasmin Board, Aidan Burrell, Tim Byrne, Eliza Dean, Emma Martin, Chris Mason, Phoebe McCracken, Sacha Richardson, Shirley Vallance and Meredith Young; Austin Hospital: Rinaldo Bellomo, Glenn Eastwood, Leah Peck and Helen Young; Fiona Stanley Hospital: Ege Eroglu, Edward Litton, Annemarie Palermo and Susan Pellicano; Flinders Medical Centre: Shailesh Bihari, Xia Jin, Russell Laver, Elisha Matheson, Kate Schwartz and Tapaswi Shrestha; Lyell McEwin Hospital: Timothy Beckingham and Natalie Soar; Monash Medical Centre: Dhiraj Bhatia, Lauren Bulfin, Timothy Crozier, Klaudija Lavrans, Julie Luong, Venkata Maduri, Michael Patterson, Chloe Peppin and Angela Wang; Queen Elizabeth Hospital: Catherine Kurenda, Sandra Peake, Nadeem Robaa and Patricia Williams; Royal Adelaide Hospital: Lukasz Badek, Stanley Bart, Marianne Chapman, Michael Davies, Adam Deane, Sarah Doherty, Kathleen Glasby, Samuel Gluck, Robert Grieve, Palesh Karr, Joanne McIntyre, Stephanie O'Connor, Alexis Poole, Eamon Raith, Benjamin Reddi, Justine Rivett, Sandeep Sethi, Joannies Yap and Nikki Yeo; Royal Melbourne Hospital: Yasmine Aliabdelhamind, James Anstey, Deborah Barge, Kathleen Byrne, Adam Deane, Sarah Doherty, Paul Emery, Peter Forrest, Madeline Haile, Sandra Lussier, Tom Rechnitzer and Geoffrey Wigmore; St John of God (Murdoch): Annemarie Palermo, Susan Pellicano and Adrian Regli; St Vincent's Hospital (Melbourne): Leanne Barbazza, Barry Dixon, Jennifer Holmes, John Santamaria, Roger Smith and Antony Tobin.

\section{Compliance with ethical standards}

\section{Conflict of interest}

Dr. Beasley reports receiving grant support from Fisher and Paykel Healthcare; and Dr. Freebairn, receiving travel support from Hamilton Medical and IMT (Bellavista). No other potential conflict of interest relevant to this article was reported.

\section{Publisher's Note}

Springer Nature remains neutral with regard to jurisdictional claims in published maps and institutional affiliations.

Received: 31 May 2020 Accepted: 20 July 2020

Published online: 18 August 2020

\section{References}

1. Girardis M, Alhazzani W, Rasmussen BS (2019) What's new in oxygen therapy? Intensive Care Med 45:1009-1011

2. Skrifvars MB, Olasveengen TM, Ristagno G (2019) Oxygen and carbon dioxide targets during and after resuscitation of cardiac arrest patients. Intensive Care Med 45:284-286
3. Pilcher J, Weatherall M, Shirtcliffe P, Bellomo R, Young P, Beasley R (2012) The effect of hyperoxia following cardiac arrest: a systematic review and meta-analysis of animal trials. Resuscitation 83:417-422

4. Kilgannon JH, Jones AE, Parrillo JE, Dellinger RP, Milcarek B, Hunter K, Shapiro NI, Trzeciak S, Emergency Medicine Shock Research Network Investigators (2011) Relationship between supranormal oxygen tension and outcome after resuscitation from cardiac arrest. Circulation 123:2717-2722

5. Kilgannon JH, Jones AE, Shapiro NI, Angelos MG, Milcarek B, Hunter K, Parrillo JE, Trzeciak S, Emergency Medicine Shock Research Network Investigators (2010) Association between arterial hyperoxia following resuscitation from cardiac arrest and in-hospital mortality. JAMA 303:2165-2171

6. Roberts BW, Kilgannon JH, Hunter BR, Puskarich MA, Pierce L, Donnino M, Leary M, Kline JA, Jones AE, Shapiro NI, Abella BS, Trzeciak S (2018) Association between early hyperoxia exposure after resuscitation from cardiac arrest and neurological disability: prospective multicenter protocoldirected cohort Study. Circulation 137:2114-2124

7. Helmerhorst HJ, Roos-Blom MJ, van Westerloo DJ, Abu-Hanna A, de Keizer NF, de Jonge E (2015) Associations of arterial carbon dioxide and arterial oxygen concentrations with hospital mortality after resuscitation from cardiac arrest. Crit Care 19:348

8. Vaahersalo J, Bendel S, Reinikainen M, Kurola J, Tiainen M, Raj R, Pettila V, Varpula T, Skrifvars MB, FINNRESUSCI Study Group (2014) Arterial blood gas tensions after resuscitation from out-of-hospital cardiac arrest: associations with long-term neurologic outcome. Crit Care Med 42:1463-1470

9. Bellomo R, Bailey M, Eastwood GM, Nichol A, Pilcher D, Hart GK, Reade MC, Egi M, Cooper DJ, Study of Oxygen in Critical Care G (2011) Arterial hyperoxia and in-hospital mortality after resuscitation from cardiac arrest. Crit Care 15:R90

10. Ebner F, Ullen S, Aneman A, Cronberg T, Mattsson N, Friberg H, Hassager C, Kjaergaard J, Kuiper M, Pelosi P, Unden J, Wise MP, Wetterslev J, Nielsen N (2019) Associations between partial pressure of oxygen and neurological outcome in out-of-hospital cardiac arrest patients: an explorative analysis of a randomized trial. Crit Care 23:30

11. Jakkula P, Reinikainen M, Hastbacka J, Loisa P, Tiainen M, Pettila V, Toppila J, Lahde M, Backlund M, Okkonen M, Bendel S, Birkelund T, Pulkkinen A, Heinonen J, Tikka T, Skrifvars MB, COMACARE Study Group (2018) Targeting two different levels of both arterial carbon dioxide and arterial oxygen after cardiac arrest and resuscitation: a randomised pilot trial. Intensive Care Med 44:2112-2121

12. Investigators I-R, the A, New Zealand Intensive Care Society Clinical Trials G, Mackle D, Bellomo R, Bailey M, Beasley R, Deane A, Eastwood G, Finfer S, Freebairn R, King V, Linke N, Litton E, McArthur C, McGuinness S, Panwar $R$, Young $P$ (2020) Conservative oxygen therapy during mechanical ventilation in the ICU. N Engl J Med 382:989-998

13. Mackle DM, Bailey MJ, Beasley RW, Bellomo R, Bennett VL, Deane AM, Eastwood GM, Finfer S, Freebairn RC, Litton E, Linke NJ, McArthur CJ, McGuinness SP, Panwar R, Young PJ (2018) Protocol summary and statistical analysis plan for the intensive care unit randomised trial comparing two approaches to oxygen therapy (ICU-ROX). Crit Care Resusc 20:22-32

14. Neumar RW, Nolan JP, Adrie C, Aibiki M, Berg RA, Bottiger BW, Callaway C, Clark RS, Geocadin RG, Jauch EC, Kern KB, Laurent I, Longstreth WT $J$ r, Merchant RM, Morley P, Morrison LJ, Nadkarni V, Peberdy MA, Rivers EP, Rodriguez-Nunez A, Sellke FW, Spaulding C, Sunde K, Vanden Hoek $T$ (2008) Post-cardiac arrest syndrome: epidemiology, pathophysiology, treatment, and prognostication. Circulation 118:2452-2483

15. Ridgeon E, Bellomo R, Myburgh J, Saxena M, Weatherall M, Jahan R, Arawwawala D, Bell S, Butt W, Camsooksai J, Carle C, Cheng A, Cirstea E, Cohen J, Cranshaw J, Delaney A, Eastwood G, Eliott S, Franke U, Gantner D, Green C, Howard-Griffin R, Inskip D, Litton E, Maclsaac C, McCairn A, Mahambrey T, Moondi P, Newby L, O'Connor S, Pegg C, Pope A, Reschreiter H, Richards B, Robertson M, Rodgers H, Shehabi Y, Smith I, Smith J, Smith N, Tilsley A, Whitehead C, Willett E, Wong K, Woodford C, Wright S, Young P (2016) Validation of a classification system for causes of death in critical care: an assessment of inter-rater reliability. Crit Care Resusc 18:50-54

16. Schoenfeld DA, Bernard GR, Network A (2002) Statistical evaluation of ventilator-free days as an efficacy measure in clinical trials of treatments for acute respiratory distress syndrome. Crit Care Med 30:1772-1777

17. Koenker RO, d'Orey V (1993) Computing regression quantiles. Appl Stat 43:410-414 
18. Young PJ, Nickson CP, Perner A (2020) When should clinicians act on non-statistically significant results from clinical trials? JAMA 323:2256
19. Sandroni C, Skrifvars MB, Soar J (2019) Vasopressors, antiarrhythmics, oxygen, and intubation in out-of-hospital cardiac arrest: possibly less is more. Intensive Care Med 45:1454-1458 